\title{
STUDY OF LEFT VENTRICULAR MASS INDEX IN NEWLY DETECTED TYPE 2 DIABETES MELLITUS SUBJECTS
}

\author{
Manjunath Shepur1, Indumathi S2, Harish Kiran ${ }^{3}$
}

${ }_{1}^{1}$ Senior Resident, Department of Medicine, Father Muller Medical College, Mangaluru, Karnataka, India.

${ }^{2}$ Assistant Professor, Department of Medicine, Subbaiah Medical College, Shivamogga, Karnataka, India.

${ }^{3}$ Assistant Professor, Department of Radiology, Subbaiah Medical College, Shivamogga, Karnataka, India.

\section{ABSTRACT}

\section{BACKGROUND}

Diabetics are at 2-3 times higher risk for cardiac disease than non-diabetics. Increased Left Ventricular Mass Index (LVMI) may lead to the increased cardiovascular risk, because LVH is an important prognostic sign and it is an independent risk factor for sudden cardiac death.

The objective of the study is to find out the prevalence of abnormal LVMI in newly detected type 2 DM subjects.

\section{MATERIALS AND METHODS}

This is a descriptive study. A total of 50 newly detected type 2 DM subjects selected from KR Hospital attached to Mysore Medical College and Research Institute. They were examined for height, weight, BMI and BSA. They underwent routine investigations, HbA1c and 2D-Echocardiography. Left ventricular mass index of these patients was calculated using 2D-Echo.

\section{RESULTS}

Mean age was $50.26 \pm 9.10$ (SD), male-to-female ratio was $1.5: 1 ; 28 \%$ were in obesity group. As BMI increased there was increased occurrence of abnormal LVMI in both male and female subjects. Subjects who had LVH with $>5$ score in Romhilt and Estes criteria had $100 \%$ abnormal LVMI compared to those with $<5$ had $41.4 \%$, which was statistically significant $(p<0.00)$. There is increased incidence of abnormal LVMI with increase in mean HbA1c, which was statistically significant $(\mathrm{p}<0.012)$.

\section{CONCLUSION}

Incidence of abnormal Left Ventricular Mass Index (LVMI) increases with loss of diabetic control and increase in Body Mass Index (BMI) and can be present even in newly detected type 2 DM. Hence, early diagnosis and good control of type 2 DM is important which may reduce the incidence of abnormal LVMI.

\section{KEY WORDS}

BMI, HbA1c, Left Ventricular Mass Index (LVMI), Newly Detected Type 2 DM.

HOW TO CITE THIS ARTICLE: Shepur M, Indumathi S, Kiran H. Study of left ventricular mass index in newly detected type 2 diabetes mellitus subjects. J. Evolution Med. Dent. Sci. 2018;7(35):3858-3862, DOI: 10.14260/jemds/2018/864

\begin{abstract}
BACKGROUND
Cardiovascular complications are increased in individuals with Diabetes Mellitus (DM), both type 1 and type 2 DM. The Framingham Heart Study showed a marked increase in Coronary Artery Disease (CAD), Myocardial Infarction (MI) and sudden death in diabetics. There are many risk factors for cardiac disease in diabetics that include dyslipidaemia, hypertension, obesity, reduced physical activity, cigarette smoking, microalbuminuria, macroalbuminuria, an elevation of serum creatinine and an abnormal platelet function. ${ }^{1}$ Heart disease account for the highest mortality in diabetics, mainly due to coronary artery disease. Even in population with low cardiovascular risk, presence of diabetes itself is associated with an increased incidence of cardiovascular death.
\end{abstract}

\section{Cardiac Involvement in Diabetes Mellitus}

A substantial morbidity and mortality in diabetics is due to

'Financial or Other Competing Interest': None.

Submission 10-07-2018, Peer Review 07-08-2018,

Acceptance 14-08-2018, Published 27-08-2018.

Corresponding Author:

Dr. Indumathi $S$,

\#HIG 8/B, Rudramsha House,

KHB Colony, Hudco, Near Priyadarshini School,

Kallahalli, Shimoga-577201, Karnataka, India.

E-mail:drindu126@gmail.com

DOI: $10.14260 /$ jemds $/ 2018 / 864$ cardiovascular disease. The cardiac manifestation in majority of diabetics is due to-

- Atherosclerotic coronary artery disease.

- Hypertensive heart disease.

- Non-coronary cardiac involvement.

- Cardiac autonomic neuropathy.

- Diabetic cardiomyopathy.

Left Ventricular Hypertrophy (LVH) is an independent risk factor for cardiac events and is often present in diabetics. The possible contributions of hyperinsulinaemia and hyperglycaemia to Left Ventricular Mass (LVM) are suggested in the normotensive and hypertensive subjects without diabetes, but there are only few studies that examined the risk factors related to LVM in type 2 DM patients without hypertension. Echocardiography accurately estimates LVMI and it has been proven to be a more sensitive tool for the detection of LVH by calculating LVMI than other techniques. ${ }^{1}$ Early detection of abnormal LVMI guides in the early management of left ventricular hypertrophy and prevention of complications associated with $\mathrm{LVH}$, hence all the newly detected type 2 DM should be screened for left ventricular mass and LVMI by 2D-echocardiography. ${ }^{2}$ 


\section{Aetiopathogenesis of Left Ventricular Hypertrophy}

Left ventricular hypertrophy occurs in physiologic conditions and in pathologic conditions including myocardial diseases or as an adaptive process to abnormal loading conditions.

Physiologic hypertrophic remodelling of the athlete heart load-induced hypertrophy.

According to the law of Laplace, wall stress is related to the pressure $(\mathrm{P})$ in the cavity, the radius of the cavity $(\mathrm{r})$ and the wall thickness (h) as follows-

Wall stress $=\mathrm{P}^{*} \mathrm{r} / 2^{*} \mathrm{~h}$

Accordingly, when there is an increase in afterload, wall thickness will increase which is an adaptive process in order to maintain wall stress normal. The most common pathologies, which leads to an increase in left ventricular afterload are systemic hypertension and aortic stenosis with the consequence to develop concentric hypertrophy. The most common pathologies causing volume overload are aortic regurgitation and mitral regurgitation. ${ }^{3}$

- Blood Pressure and Hypertension. 4

- Diabetes and the Metabolic Syndrome.

\section{Other Risk Factors}

Environmental exposures such as alcohol consumption, excess salt intake, smoking and decreased physical activity have been associated to increase LV mass.

\section{Left Ventricular Mass}

- Increase in left ventricular mass defines left ventricular hypertrophy. It is an independent risk factor for cardiovascular morbidity and mortality. Left ventricular mass can be assessed by imaging modalities such as cardiac MRI, but most non-invasive and easily done technique for estimation of the left ventricular mass will be echocardiography.

Calculating Mass (Left Ventricular Mass Formulas) ${ }^{5}$

- Original calculations from Troy and co-workers were the first to be recommended as standard to estimate LV mass from M-mode measurements (Formula 1).

- $\quad$ Formula 1: LV mass (Troy) $=1.05$ ([LVIDD + PWTD + IVSTD ${ }^{3}-$ [LVIDD] $^{3}$ ) g.

- Formula 2: LV mass (Penn) $=1.04([$ LVIDD + PWTD + IVSTD $]^{3}-\left[\right.$ [LVIDD] $\left.{ }^{3}\right)-13,6 \mathrm{~g}$.

- Formula 3: LV mass (ASE): 0.8 (1.04 ([LVIDD + PWTD + IVSTD $\left.\left.]^{3-}[\text { LVIDD }]^{3}\right)\right)+0,6$ g.

Where: LVIDD= Left Ventricular Internal Diameter in Diastole

PWTD= Posterior Wall Thickness in Diastole

IVSTD $=$ Interventricular Septum Thickness in Diastole.

- $\quad$ The current recommended formula (ASE equation) for estimation of left ventricular mass is based on modelling the left ventricle as a prolate ellipse of revolution. ${ }^{5}$

- $\quad$ LVM Index (LVMI) is calculated by dividing the LVM with the surface area.

- $\quad$ BSA is measured using the following formula: 6 $(0.0001) \times(71.84) \times($ Weight in $\mathrm{kg}) 0.425 \times($ Height in $\mathrm{cm})^{0.725}$

\begin{tabular}{|c|c|c|c|c|}
\hline $\begin{array}{c}\text { LVMI } \\
\text { (LVM/BSA) }\end{array}$ & $\begin{array}{c}\text { Reference } \\
\text { Range }\end{array}$ & $\begin{array}{c}\text { Mildly } \\
\text { Abnormal }\end{array}$ & $\begin{array}{c}\text { Moderately } \\
\text { Abnormal }\end{array}$ & $\begin{array}{c}\text { Severely } \\
\text { Abnormal }\end{array}$ \\
\hline Women & $43-95$ & $96-108$ & $109-121$ & $>122$ \\
\hline Men & $49-115$ & $116-131$ & $132-148$ & $>149$ \\
\hline
\end{tabular}

Other Imaging Methods/ Autopsy is Gold Standard, because it objectively Measures LV Mass

1. Angiography.

2. Radioisotopic gated myocardial perfusion imaging with 99mTc-Sestamibi. ${ }^{47}$

3. Computed tomography.

4. Magnetic resonance imaging.

5. 3D echocardiography.

\section{Aims and Objectives}

The objectives of the study is to find out the prevalence of abnormal Left Ventricular Mass Index (LVMI) in newly detected type 2 diabetic subjects.

\section{MATERIALS AND METHODS}

- This is a descriptive study. The present study was conducted on newly detected diabetic subjects admitted to KR Hospital, Mysore from December 2013 to December 2014 (12 months).

- $\quad$ Sample size was 50. Sample size was taken conveniently. Sampling method adopted was purposive sampling.

\section{Inclusion Criteria}

- $\quad$ Newly detected type 2 diabetes mellitus subjects.

- $\quad$ Age group between 35-65 years.

\section{Exclusion Criteria}

Renal failure with secondary hypertension.

\section{Method of Collection of Data}

Sample was taken from newly detected Type 2 Diabetic subjects who were admitted to KR Hospital, Mysore.

Informed consent was obtained from all the subjects enrolled in the study after explaining to them in detail about the study in their own language.

The subjects selected on basis of inclusion and exclusion criteria were subjected to routine history and physical examination and lab assessment. History of smoking and alcohol was taken. In general physical examination, height and weight was checked and BMI was calculated. Patient was examined for signs of retinopathy by examination of the fundus and peripheral neuropathy by CNS examination. Nephropathy was assessed by laboratory assessment like urine routine and blood urea, serum creatinine.

\section{Blood Investigations}

The patient underwent routine investigations Fasting blood glucose, Postprandial blood glucose, HbA1c, Blood urea, Serum creatinine, Urine routine (Albumin, Sugar, Micro), Lipid profile, Chest x-ray, ECG.

\section{D-Echocardiography}

- After the above investigations, patient underwent 2D echocardiography and looked for any abnormality and left ventricular mass was calculated by using the following indices. 
- $\quad$ LVIDD $=$ Left Ventricular Internal Diameter in Diastole

- $\quad$ PWTD = Posterior Wall Thickness in Diastole

- $\quad$ IVSTD = Interventricular Septum Thickness in Diastole.

Then using the above values, left ventricular mass was calculated by using the present recommended ASE equation. LV mass (ASE): 0.8 (1.04 ([LVIDD + PWTD + IVSTD] ${ }^{3}$ $\left[\right.$ LVIDD $\left.\left.^{3}\right)\right)+0.6 \mathrm{~g}$

Body Surface Area is measured using the Dubois and Dubois formula-

$(0.0001) \times(71.84) \times(\text { Weight in } \mathrm{kg})^{0.425} \times(\text { Height in } \mathrm{cm})^{0.725}$

Then, Left Ventricular Mass Index (LVMI) was calculated by using the formula- LV mass/body surface area.

\section{Statistical Analysis}

Data analysis was done using SPSS 16 version. Both descriptive and inferential statistics were employed for data analysis. Data was analysed using Chi-square test.

\section{RESULTS}

\begin{tabular}{|l|l|l|l|}
\hline Age in Years & Male (n=30) & Female (n=20) & Total $(n=50)$ \\
\hline
\end{tabular}

\begin{tabular}{|c|c|c|c|}
\hline & & & \\
\hline & & & \\
\hline $45-54$ & 10 & 9 & $19(38 \%)$ \\
\hline $55-65$ & 12 & 6 & $18(36 \%)$ \\
\hline
\end{tabular}

In our study, the incidence of newly detected type 2 diabetes mellitus was more common in patients of 45-54 years' age group (38\%). Mean age was $50.26 \pm 9.107$ (SD) years in the present study. Mean age in male was $50.73 \pm 9.62$ years and in females was $49.55 \pm 8.47$ years. The incidence was more in male patients in all the age groups.

\begin{tabular}{|c|c|c|}
\hline Sex & Number (n= 50) & Percentage \\
\hline Male & 30 & $60 \%$ \\
\hline Female & 20 & $40 \%$ \\
\hline Table 2. Sex distribution of newly detected Type 2 DM \\
patients in the Present Study \\
\hline
\end{tabular}

There were 30 male and 20 female type 2 DM patients in the present study. Male-to-female ratio in the present study was 1.5: 1.

\begin{tabular}{|c|c|c|c|}
\hline BMI & Male (n=30) & Female (n=20) & Total (n=50) \\
\hline $18.5-22.99$ & $16(53.3 \%)$ & $10(50 \%)$ & $26(52 \%)$ \\
\hline $23-24.99$ & $6(20 \%)$ & $4(20 \%)$ & $10(20 \%)$ \\
\hline$>25.0$ & $8(26.7 \%)$ & $6(30 \%)$ & $14(28 \%)$ \\
\hline \multicolumn{3}{|c|}{ Table 3. BMI (Body Mass Index) distribution of newly } \\
detected Type 2 DM in the Present Study \\
\hline
\end{tabular}

In the present study, the newly detected type $2 \mathrm{DM}$ with normal BMI (18.5-22.99) were 26 (52\%), overweight (23$24.99)$ were $10(20 \%)$, obesity ( $>25.0)$ were $14(28 \%)$ and underweight $(<18.5)$ were nil $(0 \%)$. Newly detected DM with obesity was more prevalent in females $(30 \%)$ than in males (26.7\%).

\begin{tabular}{|c|c|c|c|c|c|c|}
\hline $\begin{array}{c}\text { Age In } \\
\text { Years }\end{array}$ & $\begin{array}{c}\text { Normal } \\
(\mathbf{n = 2 4 )}\end{array}$ & $\begin{array}{c}\text { Mildly } \\
\text { Abnormal } \\
\text { LVMI } \\
(\mathbf{n = 1 4 )}\end{array}$ & $\begin{array}{c}\text { Moderately } \\
\text { Abnormal } \\
\text { LVMI } \\
(\mathbf{n = 6})\end{array}$ & $\begin{array}{c}\text { Severely } \\
\text { Abnormal } \\
\text { LVMI } \\
\text { (n=6) }\end{array}$ & $\begin{array}{c}\text { Total } \\
\text { Total } \\
(\mathbf{n = 5 0})\end{array}$ & $\begin{array}{c}\text { Abnormal } \\
\text { LVMI } \\
(\mathbf{n = 2 6})\end{array}$ \\
\hline $35-44$ & 7 & 5 & 1 & 0 & 13 & 6 \\
& $(53.8 \%)$ & $(38.5 \%)$ & $(7.7 \%)$ & $(0 \%)$ & $(100 \%)$ & $(46.2 \%)$ \\
\hline $45-54$ & 7 & 5 & 3 & 4 & 19 & 12 \\
& $(36.8 \%)$ & $(26.4 \%)$ & $(15.8 \%)$ & $(21 \%)$ & $(100 \%)$ & $(63.2 \%)$ \\
\hline $55-64$ & 10 & 4 & 2 & 2 & 8 & 8 \\
& $(55.6 \%)$ & $(22.2 \%)$ & $(11.1 \%)$ & $(11.1 \%)$ & $(100 \%)$ & $(44.4 \%)$ \\
\hline & $(48 \%)$ & $(28 \%)$ & $(12 \%)$ & $(12 \%)$ & & \\
\hline
\end{tabular}

Table 4. Table showing Left Ventricular Mass Index (LVMI) of newly detected Type 2 DM in different Age Groups

$\mathrm{P}<0.563$.

Overall, incidence of normal LVMI was 48\%, mildly abnormal LVMI being 28\%, moderately abnormal LVMI was $12 \%$ and severely abnormal LVMI was $12 \%$ in all the age groups in the present study. The incidence of newly detected DM with abnormal LVMI was increased in age group of 45-54 years with $12(63.2 \%)$ patients compared to 55-64 years' age group with 8 (44.4\%) patients and 35-44 years' age group with $6(46.2 \%)$ patients. The difference was not statistically significant $(\mathrm{p}<0.563)$.

\begin{tabular}{|c|c|c|c|c|c|c|}
\hline BMI & $\begin{array}{c}\text { Normal } \\
\text { LVMI } \\
(n=16)\end{array}$ & $\begin{array}{c}\text { Mildly } \\
\text { Abnorma } \\
\text { LVMI } \\
(\mathrm{n}=10)\end{array}$ & $\begin{array}{l}\text { Moderately } \\
\text { Abnormal } \\
\text { LVMI }(n=3)\end{array}$ & $\begin{array}{c}\text { Severely } \\
\text { Abnormal } \\
\text { LVMI } \\
(n=1)\end{array}$ & $\begin{array}{l}\text { Total } \\
(n=30)\end{array}$ & $\begin{array}{c}\text { Total } \\
\text { Abnormal } \\
\text { LVMI }\end{array}$ \\
\hline $\begin{array}{l}18.51- \\
22.99 \\
\end{array}$ & $\begin{array}{c}10 \\
(62.5 \%)\end{array}$ & $\begin{array}{c}6 \\
(37.5 \%)\end{array}$ & $\begin{array}{c}0 \\
(0 \%)\end{array}$ & $\begin{array}{c}0 \\
(0 \%)\end{array}$ & 16 & 6 \\
\hline \begin{tabular}{|l|}
$23.0-$ \\
24.99
\end{tabular} & $\begin{array}{c}3 \\
(50 \%)\end{array}$ & $\begin{array}{c}2 \\
(33.3 \%)\end{array}$ & $\begin{array}{c}0 \\
(0 \%)\end{array}$ & $\begin{array}{c}1 \\
(16.7 \%)\end{array}$ & 6 & 3 \\
\hline$>25$ & $\begin{array}{c}3 \\
(37.5 \%)\end{array}$ & $\begin{array}{c}2 \\
(25 \%)\end{array}$ & $\begin{array}{c}3 \\
(37.5 \%)\end{array}$ & $\begin{array}{c}0 \\
(0 \%)\end{array}$ & 8 & 5 \\
\hline
\end{tabular}

Table 5. Correlation between LVMI and BMI of newly detected Type 2 DM male patients in the Present Study

$$
\mathrm{P}<0.041
$$

$62.5 \%$ of patients with newly detected male type $2 \mathrm{DM}$ patients with BMI > 25 had abnormal LVMI compared to $50 \%$ of male patients with BMI 23-24.99 and 37.5\% of male patients with BMI 18.51-22.99, which was statistically significant $(\mathrm{p}<0.041)$. Severely abnormal LVMI was seen only in male patients with BMI 23-24.99. This shows as BMI is increased there is increased occurrence of abnormal LVMI in male patients with newly detected type $2 \mathrm{DM}$.

\begin{tabular}{|c|c|c|c|c|c|c|}
\hline $\begin{array}{c}\text { Romhilt } \\
\text { and } \\
\text { Estes } \\
\text { Criteria } \\
\text { Points }\end{array}$ & $\begin{array}{c}\text { Normal } \\
\text { LVMI } \\
(\mathbf{n = 2 4 )}\end{array}$ & $\begin{array}{c}\text { Mildly } \\
\text { Abnormal } \\
\text { LVMI } \\
(\mathbf{n = 1 4 )}\end{array}$ & $\begin{array}{c}\text { Moderately } \\
\text { Abnormal } \\
\text { LVMI } \\
\text { (n=6) }\end{array}$ & $\begin{array}{c}\text { Severely } \\
\text { Abnormal } \\
\text { LVMI } \\
(\mathbf{n = 6})\end{array}$ & $\begin{array}{c}\text { Total } \\
\text { Total } \\
(\mathbf{n = 5 0})\end{array}$ & $\begin{array}{c}\text { Abnormal } \\
\text { LVMI } \\
\text { (n=26) }\end{array}$ \\
\hline$<5$ & $\begin{array}{c}24 \\
(58.6 \%)\end{array}$ & $\begin{array}{c}14 \\
(34.1 \%)\end{array}$ & $\begin{array}{c}3 \\
(7.3 \%)\end{array}$ & $\begin{array}{c}0 \\
(0 \%)\end{array}$ & 41 & 17 \\
\hline$>5$ & $\begin{array}{c}0 \\
(0 \%)\end{array}$ & $\begin{array}{c}0 \\
(0 \%)\end{array}$ & $\begin{array}{c}3 \\
(33.3 \%)\end{array}$ & $\begin{array}{c}6 \\
(66.7 \%)\end{array}$ & 9 & 9 \\
\hline
\end{tabular}

Table 6. Correlation of LVMI with ECG Criteria (Romhilt and Estes criteria of LVH) in patients with newly detected Type 2 DM in the Present Study

$\mathrm{P}<0.00$

$34.1 \%$ of patients of newly detected type 2 DM patients who had Romhilt and Estes criteria $<5$ had mildly abnormal LVMI and $7.3 \%$ of newly detected type 2 DM had moderately abnormal LVMI in the present study. 
$33.3 \%$ of newly detected type 2 DM patients who had Romhilt and Estes criteria $>5$ had moderately abnormal LVMI and $66.7 \%$ of newly detected type 2 DM patients had severely abnormal LVMI in the present study. This shows that patients with newly detected type $2 \mathrm{DM}$, who had Romhilt and Estes criteria $>5$ had $100 \%$ abnormal LVMI compared to Romhilt and Estes criteria $<5$, who had $41.4 \%$ abnormal LVMI which was statistically significant $(p<0.00)$.

\section{DISCUSSION}

Cardiac complications occurs eventually in a majority of patients with diabetes and continues to be the most important factor in overall diabetic morbidity and mortality. Since LVH is an important prognostic sign, Left Ventricular Mass Index (LVMI) becomes an independent risk factor for myocardial infarction, heart failure, ventricular arrhythmias and sudden cardiac death. Angiotensin-converting enzymes inhibitors and angiotensin receptor blockers are effective both in controlling blood pressure and reversing LVH. Hypertension occurs often in individuals with diabetes, as it does in the non-diabetic population and up to $50 \%$ diabetic individuals become hypertensive. ${ }^{7}$

In the present study, there is increased LVMI in the age group of 45-54 years (38\%). The age distribution of newly detected type $2 \mathrm{DM}$ in the present study was more in 45-54 years (38\%) with a mean age of $50.26 \pm 9.107$ years compared to Santra et al. The most common age was in the range of age 44-60 years with a mean age of 53 years. According to $\mathrm{V}$ Mohan et al there is increased prevalence of diabetes in India in the age group of 40-49 years (30\%) with a mean age of 46 years, which was comparable to the present study. According to Murilo Foppa et al LVMI progressively increases during aging, particularly parietal thickness which was seen in both normotensive and hypertensive patients.

The incidence of abnormal LVMI was $63.2 \%$ in the newly detected type $2 \mathrm{DM}$ with the age group of $45-54$ years in the present study.

The male-to-female ratio in the newly detected type $2 \mathrm{DM}$ patients was 1.5: 1 in the present study compared to Santra et al, where male-to-female ratio was 1.27: 1 , which was comparable. In the present study, the prevalence of abnormal LVMI in all new detected type 2 DM patients was $52 \%$ compared to Santra et al, where the prevalence of abnormal LVMI was 53\% which was comparable. The prevalence of abnormal LVMI in male subjects with newly detected type 2 DM was $46.7 \%$ and female was $60 \%$ compared to Santra et al. The prevalence of abnormal LVMI in male was $54 \%$ and in females was 53\%, which was comparable. According to Esko Vanninen MDJ et al, the diabetic women had increased LV mass index and decreased fractional shortening. This is comparable to our study.

In our study, there is increased incidence of abnormal LVMI with higher BMI. This was seen both in males and females, but it was statistically significant in males. The abnormal LVMI in patients with BMI of $>25$ in the present study was $35.7 \%$ compared to $\mathrm{W}$ Aljourdi et al. There is increasing LVMI with increasing BMI. The maximum mean LVMI of $43.9 \%$ was observed in patients with BMI of $>40 .{ }^{8}$

$18 \%$ of the newly detected type 2 DM patients in the present study fulfilled the Romhilt-Estes electrocardiogram criteria for LVH. It was seen in $17 \%$ of patients with newly detected type 2 DM in Bruno G et al, which was comparable with our study. ${ }^{9}$

The patients with abnormal LVMI had higher HbA1c in the newly detected type $2 \mathrm{DM}$ patients in the present study. This shows abnormal LVMI increases with loss of diabetic control as evidenced by higher $\mathrm{HbA1c}$.

\section{Limitations}

- Study sample was small.

- Effect of treatment of diabetes on LVMI was not studied.

\section{CONCLUSION}

- Mean age was $50.26 \pm 9.10$ (SD) years in the present study of newly detected type $2 \mathrm{DM}$.

- Male-to-female ratio was 1.5:1 in the present study.

- BMI distribution was $52 \%$ in normal BMI, $20 \%$ in overweight, $28 \%$ in obesity groups in the present study.

- Incidence of abnormal LVMI was more prevalent in the age group of $45-54$ years $(63.2 \%)$ compared to $35-44$ years (46.2\%) and 55-65 years (44.4\%), which was not statistically significant $(\mathrm{p}<0.563)$.

- As BMI increased, there was increased occurrence of abnormal LVMI in male patients with newly detected type $2 \mathrm{DM}(62.5 \%$ in obese compared to $58 \%$ in overweight).

- As BMI increased, there was increased occurrence of abnormal LVMI in female patients with newly detected type 2 DM (100\% in overweight compared to $83.3 \%$ in obese).

- The patients who had LVH with > 5 score in Romhilt and Estes criteria had 100\% abnormal LVMI compared to those with $<5$ had $41.4 \%$, which was statistically significant $(\mathrm{p}<0.00)$.

- There is increased incidence of abnormal LVMI with increase in mean $\mathrm{HbA1c}$, which was statistically significant $(\mathrm{p}<0.012)$.

Incidence of abnormal Left Ventricular Mass Index (LVMI) increases with loss of diabetic control and increase in Body Mass Index (BMI) and can be present even in newly detected type 2 DM. Hence, early diagnosis of type $2 \mathrm{DM}$ is important and after detection, good control of type $2 \mathrm{DM}$ is important using adequate antidiabetic drugs, medical nutrition therapy and daily exercise to maintain normal body weight which may reduce the incidence of abnormal LVMI.

\section{REFERENCES}

[1] Santra S, Basu A, Roychowdhury P, et al. Comparison of left ventricular mass in normotensive type 2 diabetes mellitus patients with that in the non-diabetic population. Journal of Cardiovascular Disease Research 2011;2(1):50-6.

[2] Vanninen E, Mustonen J, Vainio P, et al. Left ventricular function and dimensions in newly diagnosed noninsulin-dependent diabetes mellitus. The American Journal of Cardiology 1992;70(3):371-8.

[3] Bei-Fan Z. Predictive values of body mass index and waist circumference for risk factors of certain related diseases in Chinese adults: study on optimal cut-off points of body mass index and waist circumference in Chinese adults. Asia Pac J Clin Nutr 2002;11(Suppl 8):S685-S93. 
[4] Medical examination review book, vol. 2C-Textbook study guide of cardiology: by Grenzer Louis E, Flushing NY. 1974, Medical Examination Publishing Company, Inc., 136 pp. Price \$7.50. American Heart Journal 1976;92(1):127.

[5] Paczek A, Gardin JM, Hardin JM, et al. Comparison of M-mode and two-dimensional echocardiographic algorithms used to estimate left ventricular mass: The Coronary Artery Risk Development in Young Adults Study. Journal of the American Society of Echocardiography 1995;8(6):780-92.

[6] Tognon AP, Foppa M, Luft VC, et al. Reproducibility of left ventricular mass by echocardiogram in the ELSABrasil. Arquivos Brasileiros de Cardiologia 2014.
[7] Lee M, Gardin JM, Lynch JC, et al. Diabetes mellitus and echocardiographic left ventricular function in freeliving elderly men and women: The Cardiovascular Health Study. American Heart Journal 1997;133(1):36-43.

[8] Felicio JS, Ferreira SR, Plavnik FL, et al. Effect of blood glucose on left ventricular mass in patients with hypertension and type 2 diabetes mellitus. American Journal of Hypertension 2000;13(11):1149-54.

[9] Bruno G, Giunti S, Bargero G, et al. Sex-differences in prevalence of electrocardiographic left ventricular hypertrophy in Type 2 diabetes: the Casale Monferrato Study. Diabetic Medicine 2004;21(8):823-8. 